\title{
CONCEPTUAL RESTORATION 1: A BODHISATTVA TORSO FROM TIANLONGSHAN
}

Near the ancient city of Jinyang, modern Taiyuan in the Shanxi province of China, 25 caves were carved over a period of four centuries in the mountainsides of Tianlongshan. ${ }^{1}$ This region has been an important political and cultural centre since early antiquity and lies near one of the northern routes of the Silk Road. Travellers brought religious relics and ideas to Shanxi and Buddhism grew in all parts of the province. As a result, holy sites were constructed and filled with images of deities and other treasures. ${ }^{2}$ In the caves of Tianlongshan are countless wall paintings, reliefs and sculptures from the Eastern Wei (534-550), Northern Qi (550-577), and Sui (589-618) dynasties, but predominantly from the Tang (618-907). In 1933, one of the smaller Tang-dynasty sculptures from the caves of the Tianlongshan was bought by the Vereniging from the dealer C. T. Loo in Paris and is now on display in the Asian Pavilion of the Rijksmuseum in Amsterdam (fig. 1). ${ }^{3}$ We now know that this slender torso of a bodhisattva, carved in grey sandstone, was originally part of a group of seven figures in cave 14, located on the western peak of the mountain. ${ }^{4}$ Because it was connected to the wall, parts of the clothing and other fragile elements, such as the hands and feet, have been lost. Nonetheless, the figure still shows how finely the sculptures were carved and decorated at this time and gives a hint as to how precious the treasures inside the mountain must have been.

Over time, the caves of Tianlongshan were partially destroyed during religious persecutions under the Eastern Wei, Northern Zhou (557-581) and Tang dynasties or simply due to natural decay as a result of the meteorological conditions. ${ }^{5}$ Nevertheless, the most systematic destruction was due to the plundering and seizure of sculpture during war or occupation in the early 20th century (especially in the 1920's). ${ }^{6}$ This is also the reason why many of the sculptures are now part of European, American or Japanese museum collections, or are owned by private collectors. The head of the Rijksmuseum bodhisattva, for example, is now located in the British Museum in London, whereas other figures from cave 14 are in the collections of the Museum Rietberg in Zurich, the Tokyo National Museum, the Osaka Municipal Museum of Art and the Wadsworth Athenaeum in Hartford, Connecticut. ${ }^{7}$ Even though the Tianlongshan caves are not in a very good condition today,

Fig. 1 Torso of a bodhisattva, grey sandstone, $95 \times 45 \times 17 \mathrm{~cm}$., Tianlongshan (Shanxi province), around 888-1060, Rijksmuseum Amsterdam, inv.nr. AKMAK-75. there is a number of documents that allow us to conceptually reconstruct the religious site. Between 1920 and 1926, the Japanese buddhologists Tokiwa Daijo (1870-1945) and Sekino Tadashi (1868-1935), the Scandinavian art historian Osvald Sirén (1879-1966), as well as the art dealer and collector Yamanaka Sadajiro (1866-1936), all visited Tianlongshan when it was in much better condition and recorded all the caves and figures in their publications. ${ }^{8}$ The sculptures, as well as the caves themselves, were carved

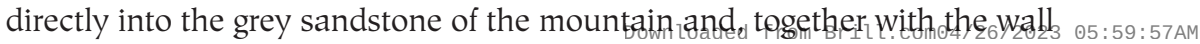




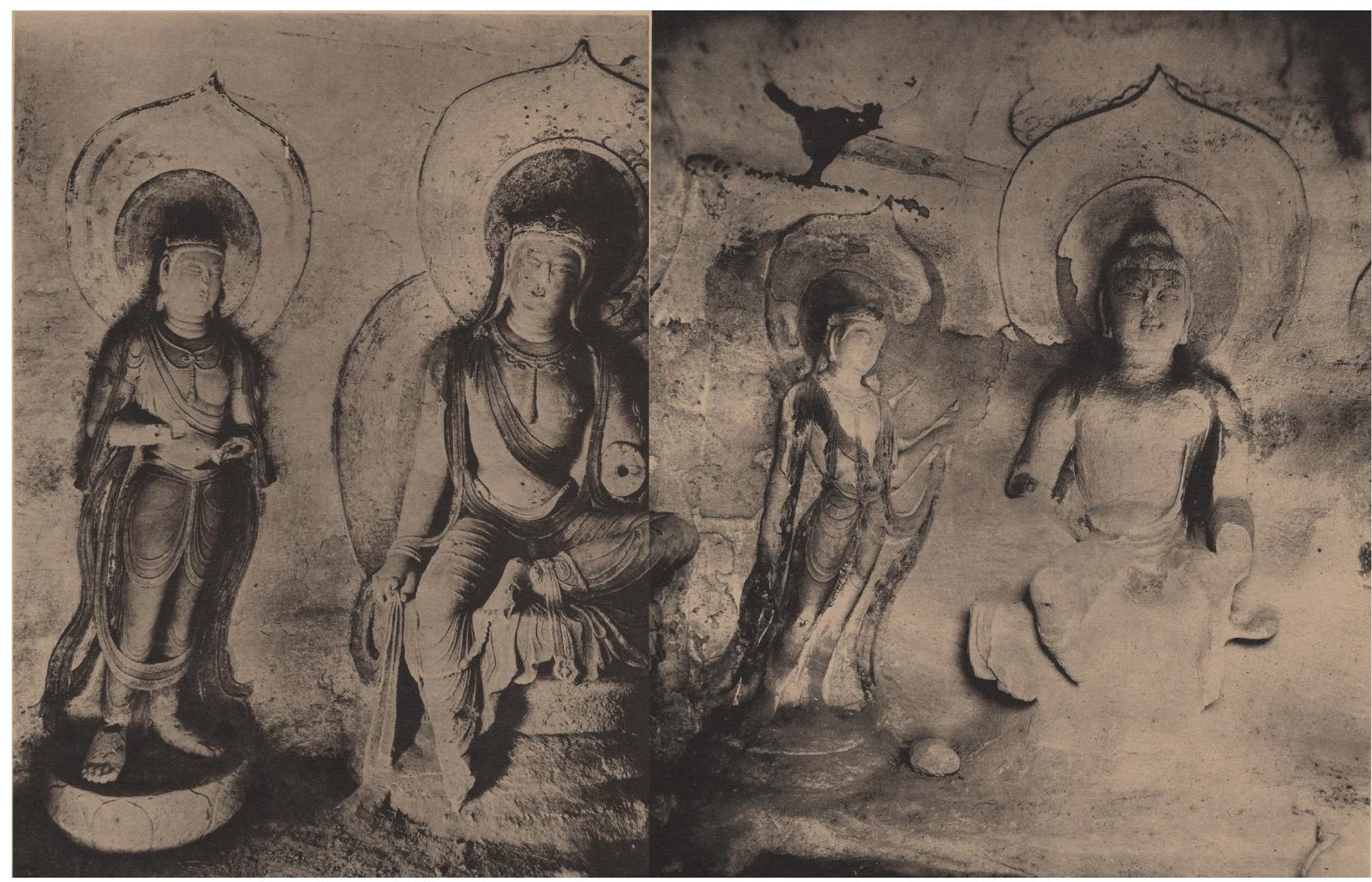

Fig. 2 (above)

Three photographs

of cave 14 at the

Tianlongshan (from

left to right) western

wall, northern wall,

eastern wall with the

small Rijksmuseum's

bodhisattva (last figure).

Fig. 3 (right)

Simplified illustration of cave 14 (upper left).

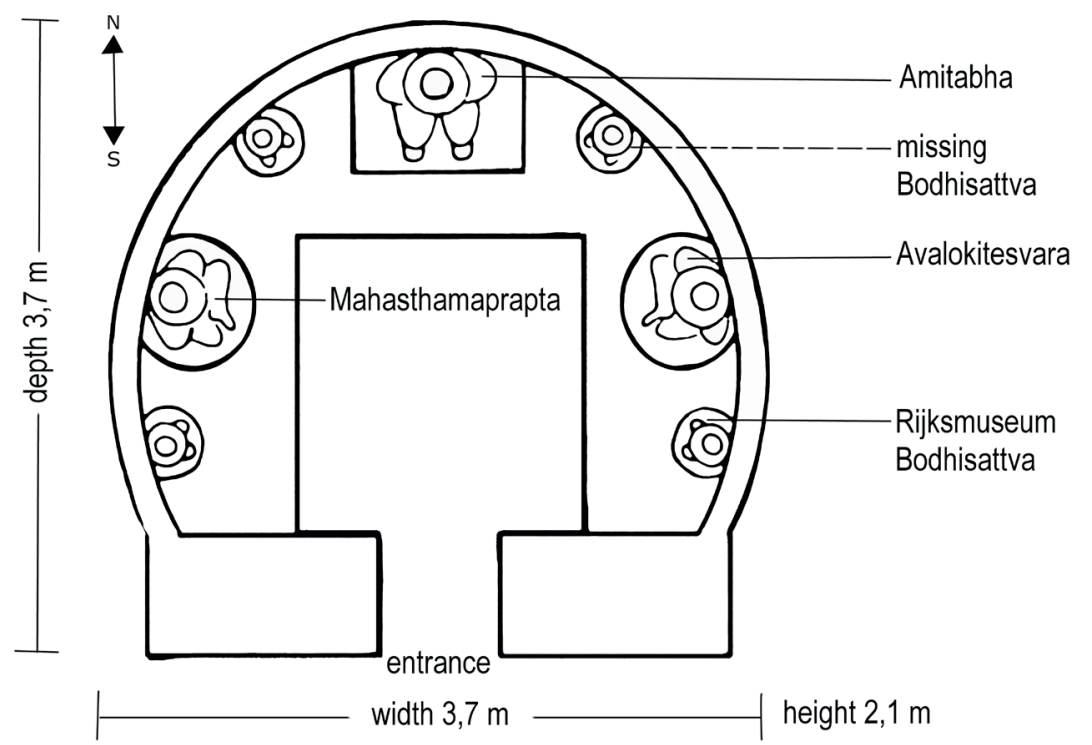


Fig. 4

Small bodhisattva on the western wall of

cave 14 with

inscription on the

left, grey sandstone,

Tianlongshan (Shanxi

province), around

888-1060, collection

unknown.

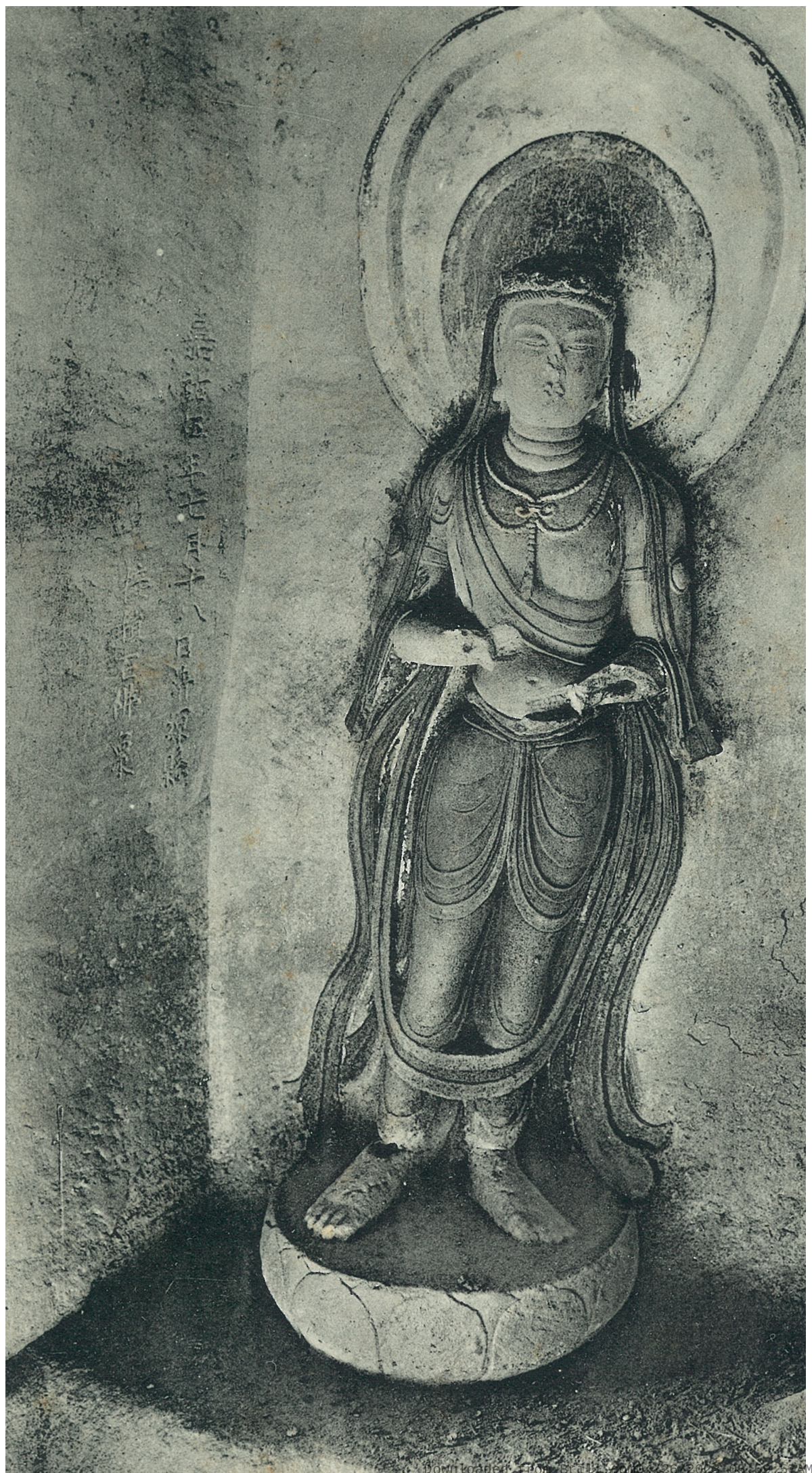


Fig. 5

Head of a bodhisattva, grey sandstone, h. $33 \mathrm{~cm}$., Tianlongshan (Shanxi province), around 888-1060, The British Museum London, 1937, inv.nr. 1013.4.

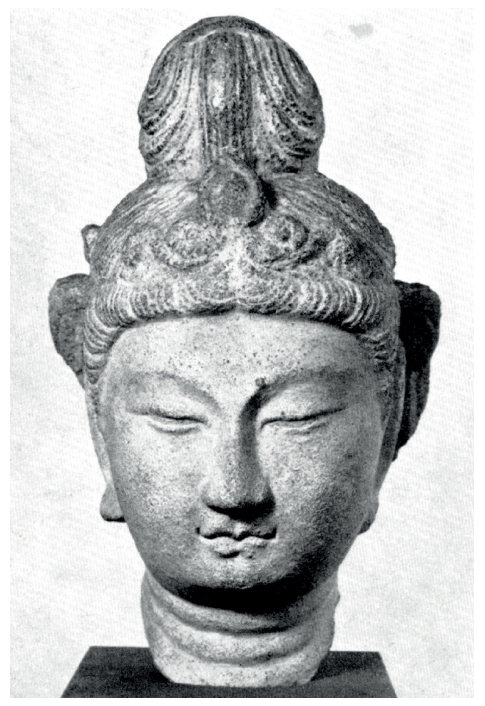

composition of all other figures. ${ }^{11}$ Except for some slight differences, for example in the garments, accessories and mudras, each figure and its paired counterpart on the opposite wall look alike. In trying to re-imagine the complete figure of the Rijksmuseum torso with the help of the photographs, it might be useful to look at the better-preserved bodhisattva from the western wall to prove that the two figures differ only slightly from each other. According to Yamanaka's documentation, which contains detailed travel reports of the Tianlongshan, two inscriptions were found inside the cave, one from the Tang and one from the Song dynasty (960-1279): 'On a propitious day of the fifth month in the first year of the Wende-period [888] in the great Tang [dynasty], [the monks] Hui Yuan, Hui Liang and Hui Jing' ${ }^{12}$ and 'On the fifth day of the fifth month in the fifth year of the Jiayu-period [1060] of the great Song [dynasty], [a place] absorbing all harm and to practice the dharma. ${ }^{13}$ This indicates that the cave was built between 888 and 1060 . The photographs of Sirén also show an inscription next to the bodhisattva on the western wall (fig. 4): 'On the eighteenth day of the seventh month in the Jia[yu?]-period [...] buddhist monk.' Unfortunately, since most of the characters are unreadable, this inscription gives very little evidence for further dating. However, aside from the inscriptions, many similar figures from the Tang caves at Tianlongshan can be compared stylistically with those of cave 14. For instance, the bodhisattvas of caves 18 and 21 demonstrate a comparable posture and proportions, as well as nearly identical garments. ${ }^{14}$ Furthermore, the heads of Buddha display an astonishing similarity to one another and all the figures show evidence of polychrome framing, mostly recognizable by the remnants of red paint.

Today, only a small number of the Tianlongshan sculptures and caves, some of them preserved in good condition and some restored, reveal information about their original polychromy. The Rijksmuseum bodhisattva has residues of red paint on the garments and white paint on the body, whereas the head in the British Museum shows an exiguous trace of turquoise on a veil fragment close to the left ear (fig. 5). It remains unclear if these paint

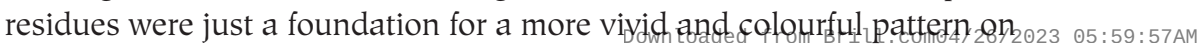


top, or already the finished coloration. However, the combination of a white skin colour with red and turquoise garments is not exceptional: at the Great Buddha hall of the Foguang Monastery on Mount Wutai in the same Shanxi province, there is a group of no less than seven Tang-dynasty figures with similarly coloured bodhisattvas (fig. 6). ${ }^{15}$ The red and green colours are used to differentiate between the inside and outside of the garments, to make the tight-fitting drapery look more vivid and three-dimensional. Furthermore, the polychromy of the sculptures often corresponds to the colours used in the wall paintings, and the coloration methods are also related. Sometimes, precious materials such as gold foil were added. ${ }^{16}$

Although the colour range is not uncommon, the composition of a Buddha and six bodhisattvas, as that in cave 14, is rare. The majority of Qi and Tang caves at Tianlongshan contain Shakyamuni-triads, in most cases showing Shakyamuni flanked by his disciples Ananda and Mahakasyapa or by the Buddhas Maitreya and Amitabha. ${ }^{17}$ So far, no example of a triad with the Buddha Maitreya as central deity has yet been found at Tianlongshan. In fact, the popularity and number of such triads declined drastically during the late Tang dynasty. ${ }^{18}$ In contrast to this development, a triad showing 'The Three Holy Ones of the Western Region' (Xifang sansheng), containing the Buddha Amitabha and the bodhisattvas Avalokitesvara and Mahastanaprapta, became very popular at around the same time. This iconography is well known from the Amitayurdhyana Sutra, ${ }^{19}$ a text promulgated from the time that Amida-Buddhism became prominent in China during the 5 th century. ${ }^{20}$ The 'Three Holy Ones of the Western Region' does not always consist of three figures, but rather differs - as do most other triads - in the variety and number of the minor bodhisattvas that accompany Amitabha, Avalokitesvara or Mahastanaprapta. On the one hand, this suggests that the figures of cave 14 may in fact belong to a triad of the 'Three Holy Ones of the Western Region', with Amitabha in the centre, Mahastanaprapta on his right and Avalokitesvara on his left, accompanied by other figures including the Rijksmuseum bodhisattva. On the other hand, it should be mentioned that there are also a lot of exceptional triad compositions, emerging from an increase in new canonical configurations and the changing iconographies of the principal deities.

During the Tang dynasty, frequently regarded as the apogee of Buddhism in China, not only did new schools and deities emerge, but also specific styles of Buddhist sculpture spread across the whole kingdom. The sculptures of Tianlongshan are expressions of this wider creativity and rapid stylistic development in the sculpture of ancient China. While concentrating on dynastic specifications, the Rijksmuseum bodhisattva bears the typical characteristics of Tang-dynastic sculpture: a stable and slightly muscular torso with broad shoulders converging in a small waist. Above the hips, the waist seems peculiarly small and slightly feminine. ${ }^{21}$ The whole body is depicted vividly, caught in a moment of movement, as if leaning to the left side. This sinuous shape first appeared under the Qi dynasty, when bodhisattva figures were portrayed slightly in motion, culminating in the twisting pose with a typical S-curve of the upper body during the Sui dynasty. ${ }^{22}$ There is also a reference to relations with Indian models of Buddhist sculpture. A three-dimensionality (almost a full plasticity) and rounded limbs are retained from this period. The face of the bodhisattya has 05:59:57 Am 


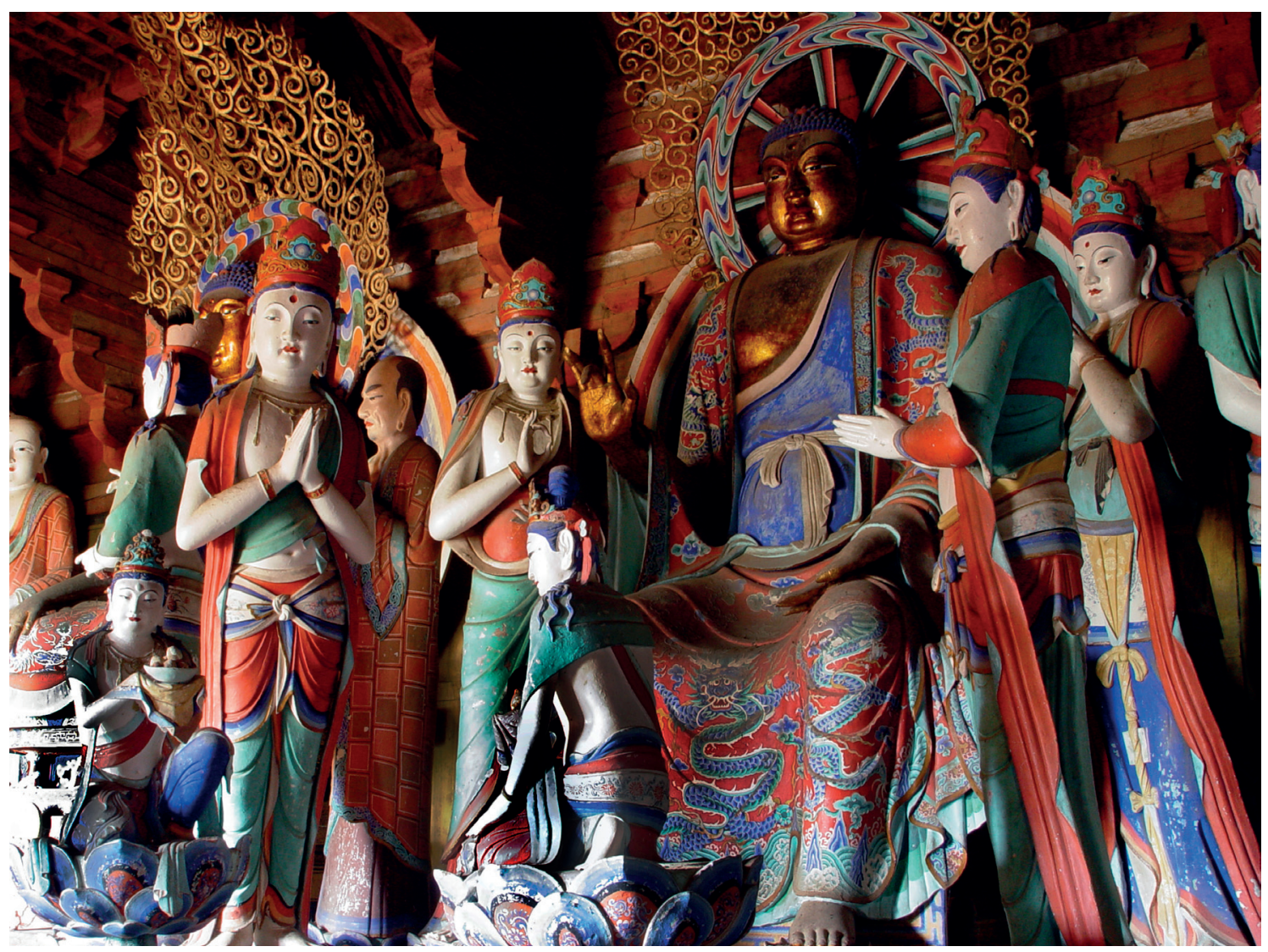

Fig. 6

Great Buddha Hall of Foguang Temple, clay figures, Wutaishan (Shanxi province), Tang dynasty. a fleshy, round shape with long, narrow eyebrows and nearly closed eyes. ${ }^{23}$ Also remarkable is the small, well-formed mouth with cherry lips. ${ }^{24}$ This kind-tempered but serious facial expression was once, under the Eastern Wei and Qi dynasties, an obvious smile with a broad mouth. ${ }^{25}$ Altogether, it seems that the most obvious changes in the portrayal of the bodhisattvas can be recognized between the Qi and Sui dynasties: The Eastern Wei and Qi bodhisattvas appear more two-dimensional, with splendiferous clothes and a lot of accessories, whereas the garments and jewellery of bodhisattvas during the Sui and Tang dynasties are simpler in form. The head of the Rijksmuseum bodhisattva in London has a crested coiffure, which might indicate the outgrowth of enlightenment (ushnisha) but is more reminiscent of the Tang-dynastic hairstyles worn by aristocratic women. ${ }^{26}$ Hair accessories and ornaments replaced the earlier headdresses, which still persisted up to the Sui dynasty. ${ }^{27}$

The garments are a relic of the origins of central Asian Buddhism and its sculpture. The undergarments, called dhôti, are those of an Indian aristocrat, perhaps those of a prince. The veils and sashes are also decorative elements from fine aristocratic robes and seem to lead a life of their own, as if fluttering

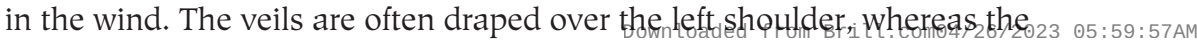


right shoulder is left bare. ${ }^{28}$ In other cases, as on the Rijksmuseum torso, the veil only slightly covers the upper body. Equally conspicuous on the torso is the evenly sorted pattern of the drapery and the extended fall of the veil. The garments look as if they are clinging to a wet body, which is known in China as the Cao Zhongda style (Caoyi chushui), derived from the depiction of figures in the paintings of the artist Cao Zhongda (flourished in the late 6th century). In fact, this stylistic feature is originally from the southern and central Asian sculptural traditions: during the period of the Gupta Empire (circa 320-550) in the region of Iran, Afghanistan, Pakistan, India and Myanmar, various styles developed and spread along the Silk Road to China..$^{29}$ The style of Mathura (northern India), for example, also has these stylistic features of evenly-sorted drapery and thin garments following the contours of the body. The fine, realistic facial features, as well as the precisely-worked strands and hairstyles, can also be found on sculptures from Gandhara (Afghanistan, Pakistan). ${ }^{30}$ Thus, the torso in the Rijksmuseum is not only evidence of the high technical skills of Chinese craftsmen during the Tang dynasty, but also an example of a long tradition of trans-cultural and religious exchange across the Asian continent as a whole.

- Melanie Katharina Weber is a graduate student at the institute of East Asian art history at the Free University of Berlin. Currently she is researching about post-war Japanese art and independent art exhibitions in the 50s and 60s at Kobe University in Japan.

\section{Literature}

Fong Chow, 'Chinese Buddhist Sculpture'. The Metropolitan Museum of Art Bulletin, New Series 23.9/1 (1965), pp. 301-24.

Jinshi Fan and Shengliang Zhao, The art of Mogao Grottoes in Dunhuang: a journey into China's Buddhist shrine, Homa \& Sekey Books, Paramus, 2009

Wu Hung, 'Reborn in Paradise: A Case Study of Dunhuang 'Sutra' Painting and its Religious, Ritual and Artistic Context' Orientations 23.5, pp. 52-60.

Yuqun Li, 'A New Understanding of the Tang Dynasty Grottoes at Tianlongshan', Orientations, 33/5 (2002), pp. 48-53.

Wei-Cheng Lin, Building a sacred mountain: the Buddhist architecture of China's Mount Wutai, University of Washington Press, Seattle, 2014.

Marylin Rhie, 'The Sculptures of T'ien Lung Shan: Reconstruction and Dating', Artibus Asia, 27/3 (1965), pp. 189-237.

Tadashi Sekino and Daijo Tokiwa, Buddhist monuments in China, Bukkyo-Shiseki Kenkyu-kwai, Tokio, 1938.

Mochizuki Shinko, Chugoku jodo kyori shi, Tokio, 1942.

Osvald Sirén, Chinese sculpture from the fifth to the fourteenth century: over 900 specimens in stone, bronze, lacquer and wood, principally from northern China. Vol 1-4, Benn, London, 1925.

Katsumi Tanabe, Alexander the Great: East-West cultural contacts from Greece to Japan, Tokyo Kokuritsu Hakubutsukan, Tokio, 2003. [exhibition catalogue]

Max Wegner, 'Ikonographie des chinesischen Maitreya', Ostasiatische Zeitschrift, 5 (1929), pp. 156-78.

Sadajiro Yamanaka, Yamanaka Sadajiro den, Ko Yamanaka Sadajiro-o Den Hensankai, Osaka, 1939. 
1. Literally translated: sky dragon's mountain.

2. Sekino and Tokiwa 1938: 17

3. Rhie 1965: 189

4. Rhie 1965: 198

5. In case of cave 14 the damage was mostly caused by water dripping.

6. Sirén 1925: 55

7. Rhie 1965: 198-99

8. These are the publications Sekino and Tokiwa 1938; Sirén 1925 and Yamanaka 1939. For further information see Literature.

9. Rhie 1965: 189

10. Yuqun 2002: 48

11. Rhie 1965: 211

12. Yamanaka 1939: 128. The monks Huiyuan, Huiliang and Huijing were probably named as patrons of the cave.

13. Yamanaka 1939: 128

14. Yuqun 2002: 49

15. Lin 2014: 10-1

16. Fan and Zhao 2009: 53

17. Sekino and Tokiwa 1938: 24-5, 29, 32-3. Yuqun 2002: 48.

18. Wegner 1929: 16-7.

19. Foshuo guan wuliangshou jing.

20. "Sutra on Visualizing the Amitayus Buddha". Wu 1992: 52, 56. Under the Emperor Xiaowen (467-499) the capital moved to Luoyang (Henan province, next to Shanxi) and a large number of caves and temples were established (i.e. the Longmen caves). Mochizuki 1942: 270.

21. Yuqun 2002: 49

22. Chow 1965: 315

23. Fan and Zhao 2009: 53

24. Rhie 1965: 218.

25. Chow 1965: 306

26. Yuqun 2002: 49

27. Chow 1965: 320

28. This habit is often ignored in a mirrored composition of figures.

29. Fan and Zhao 2009: 54

30. Tanabe 2003: 19 


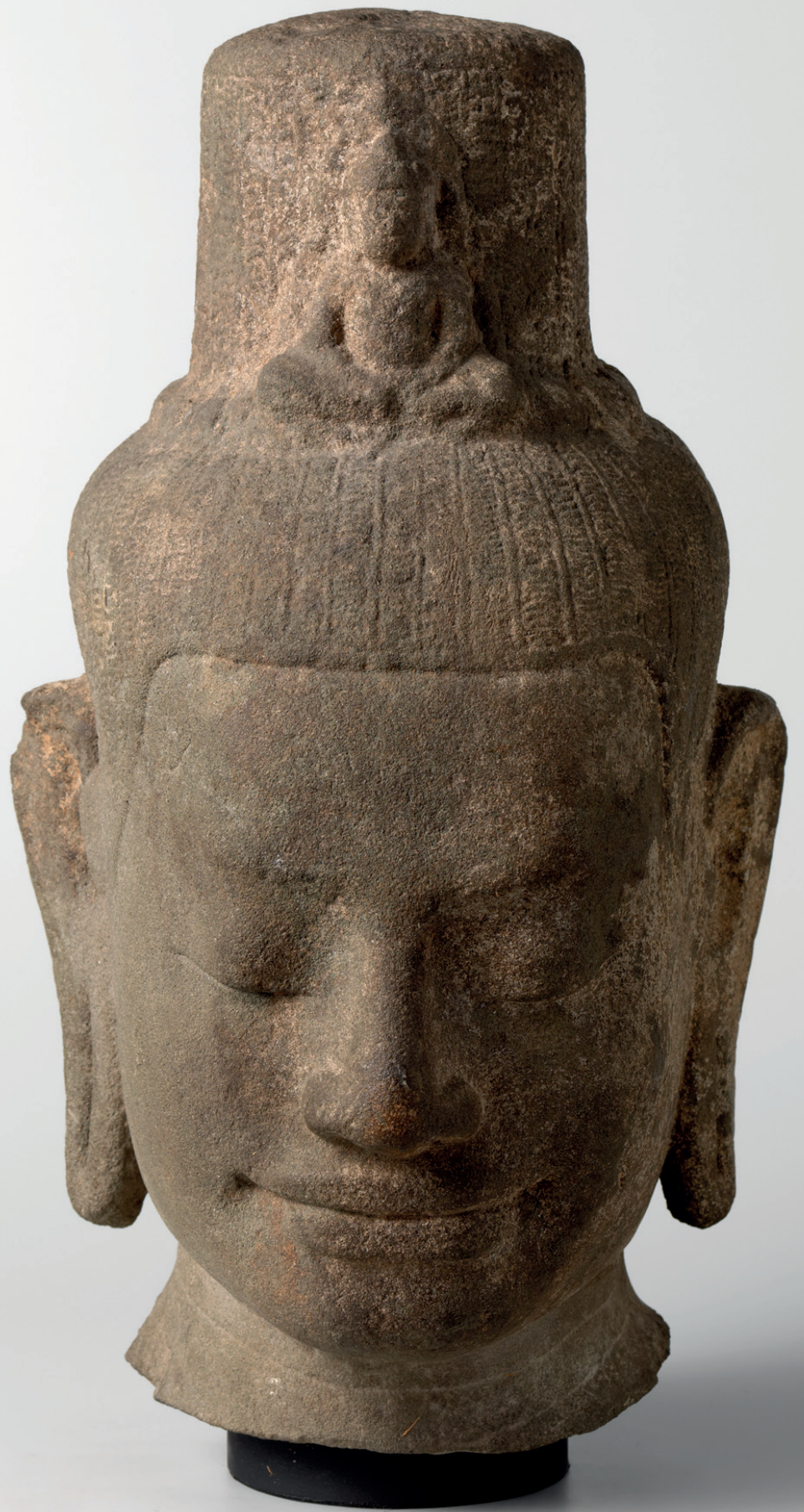

Downloaded from Brill.come4/26/2023 05:59:57AM 